\title{
APUNTES SOBRE LA ELABORACIÓN DE BIOMBOS EN LA NUEVA ESPAÑA
}

\author{
Alberto Baena Zapatero \\ Universidade Federal de Goiás (Brasil)
}

\begin{abstract}
El artículo reflexiona sobre el origen de la producción de biombos en Nueva España y su relación con el resto de manufacturas de inspiración oriental surgidas en el virreinato. Con este objetivo se interroga sobre en qué momento aparecen los primeros ejemplares, quiénes fueron los responsables de esta innovación y cuáles pudieron ser los principales centros productores.
\end{abstract}

Palabras clave: Biombos; Enconchados; Muebles; México; Globalización.

\section{NOTES ON THE PRODUCTION OF FOLDING SCREENS IN NEW SPAIN}

This study reflects on the origin of the production of folding screens in New Spain and their relationship with other manufactures of oriental inspiration that emerged in the Viceroyalty. The questions posed concern when the first examples appeared, who were the artisans responsible for this innovation and which were the possible main production centers.

Key words: Folding screens; Enconchados; Furniture; Mexico; Globalization.

\section{Introducción}

A menudo la historiografía ha destacado la importancia que tuvo el galeón de Manila sobre la cultura y el arte novohispanos. La llegada desde el último cuarto del siglo XVI de telas, porcelanas, muebles, biombos, marfiles o piezas de laca desde Asia tuvo un profundo impacto sobre el gusto de la población del virreinato. Sin embargo, el éxito de estos objetos no debe atribuirse simplemente a la mera atracción por lo "exótico", una serie de características propias de Nueva España estimularon su demanda y propiciaron la aparición de manufacturas locales. Entre éstas destacó la de biombos por su volumen y variedad, llegando a exportarse a Europa y al resto de América.

Hasta el momento se sabe muy poco sobre el origen de los biombos mexicanos, quienes pudieron ser sus autores y cuáles fueron sus posibles centros productores. Nuestro objetivo será interrogarnos sobre estas cuestiones, respondiéndolas cuando fuera posible y planteando nuevas preguntas que orienten futuras investigaciones. 


\section{El origen}

Si se investiga sobre que artesanos dieron inicio a las manufacturas de inspiración oriental en Nueva España, nos encontramos con la idea generalizada de que fue población foránea. Según esta hipótesis, artesanos asiáticos habrían llegado en alguno de los galeones de Manila o con alguna de las dos misiones diplomáticas de japoneses que atravesaron el virreinato a inicios del siglo XVII, especialmente la segunda dirigida por el samurái Hasekura. A pesar de que no se conserva mucha documentación sobre la actividad de estas comitivas, su presencia ha sido utilizada por numerosos historiadores para justificar diferentes teorías. Teresa Castelló aseguró que entre los japoneses y chinos que permanecerían en América a la vuelta de las embajadas habría artesanos que comenzarían a realizar muebles y biombos, inicialmente sobre madera y después sobre lienzo ${ }^{1}$. En su opinión, las técnicas transmitidas por estos artistas orientales a los poblanos tendrían una gran relevancia en las manufacturas mexicanas posteriores. Beatriz Sánchez Navarro, por su parte, recuerda que Agustín de Vetancourt da cuenta en el capítulo uno de su Teatro Mexicano de la existencia en México de una cofradía de chinos, naturales de Manila, de donde se podría deducir que enseñaron a los naturales sus habilidades, entre ellas la de la talla en marfil ${ }^{2}$.

Sobre las pinturas con incrustaciones de madreperla o enconchados, Julieta Ávila destaca que tanto los recursos formales (composición, dibujo y color) como la técnica empleada (en especial el uso de la tinta china) se basaron en la tradición artística oriental. Según esta tesis, debieron realizarse por chinos o japoneses afincados en el virreinato o por novohispanos formados por maestros orientales ${ }^{3}$. Sobre este mismo asunto, Sonia Ocaña también ha recurrido a los japoneses que decidieron continuar en Nueva España para explicar el origen del proceso de recreación de las lacas namban ${ }^{4}$. Recientemente, Enriqueta Olguín ha vuelto a referirse a la posibilidad de que trabajadores de maqué asiáticos desarrollaran su oficio en el virreinato 5 .

Asimismo, el anticuario Rodrigo Rivero Lake ha sugerido que el estilo y la técnica utilizados en el biombo con la Vista de la Plaza Mayor de la ciudad de México y laguna de Ixtacalco (fig. 1) indican que fue hecho por japoneses. La falta de una perspectiva de tipo europea, la presencia de nubes namban y el hecho de que el ensamblaje original de las hojas sea el tradicionalmente utilizado en Japón, ha llevado a su propietario a defender la idea de que los biombos mexicanos fueron construidos y pintados por naturales de este reino. Rivero Lake también sostiene que Miguel y Juan González, artesanos de enconchados activos en México desde finales del siglo XVII, fueron de origen japonés ${ }^{6}$.

Aunque existe un apoyo generalizado a favor de la teoría del origen foráneo, debemos subrayar el hecho de que hasta el momento no se ha presentado ninguna evidencia documental concluyente que respalde esta hipótesis. La llegada de población extranjera por la ruta del galeón de Manila fue constante durante los siglos XVII y XVIII, sin embargo, los datos obtenidos por Déborah Oropeza o Antonio García-Abásolo sobre la emigración forzosa y libre de asiáticos a Nueva España

\footnotetext{
${ }^{1}$ Castelló y Martínez, 1970.

2 Sánchez Navarro, 1985: 120.

3 Ávila Hernández, 1997. Cabe apuntar que en la restauración de enconchados del museo de América de Madrid, la investigadora Dolores Medina encontró restos de tinta sepia e negra en el diseño de las figuras pero también de lápiz. Dolores Medina, 1995.

${ }^{4}$ Ocaña, 2008: 107-153. 2013:136.

${ }^{5}$ Olguín, 2004.

${ }^{6}$ Rivero Lake, 2005: 183. Anteriormente Virginia Armella y Julieta Ávila habían sugerido que los hermanos González pudieran ser chinos (Armella de Aspe, 1990. Ávila Hernández, 1997). Sin embargo, los documentos notariales publicados por Guillermo Tovar de Teresa inclinaron a la historiografía a considerarlos mexicanos, si bien aun no es posible afirmarlo con rotundidad. García Sáiz, 1992. Ocaña, 2013.
}

Arch. esp. arte, LXXXVIII, 350, ABRIL-JUNIO 2015, 173-188 ISSN: 0004-0428, eISSN: 1988-8511, doi: 10.3989/aearte.2015.11 


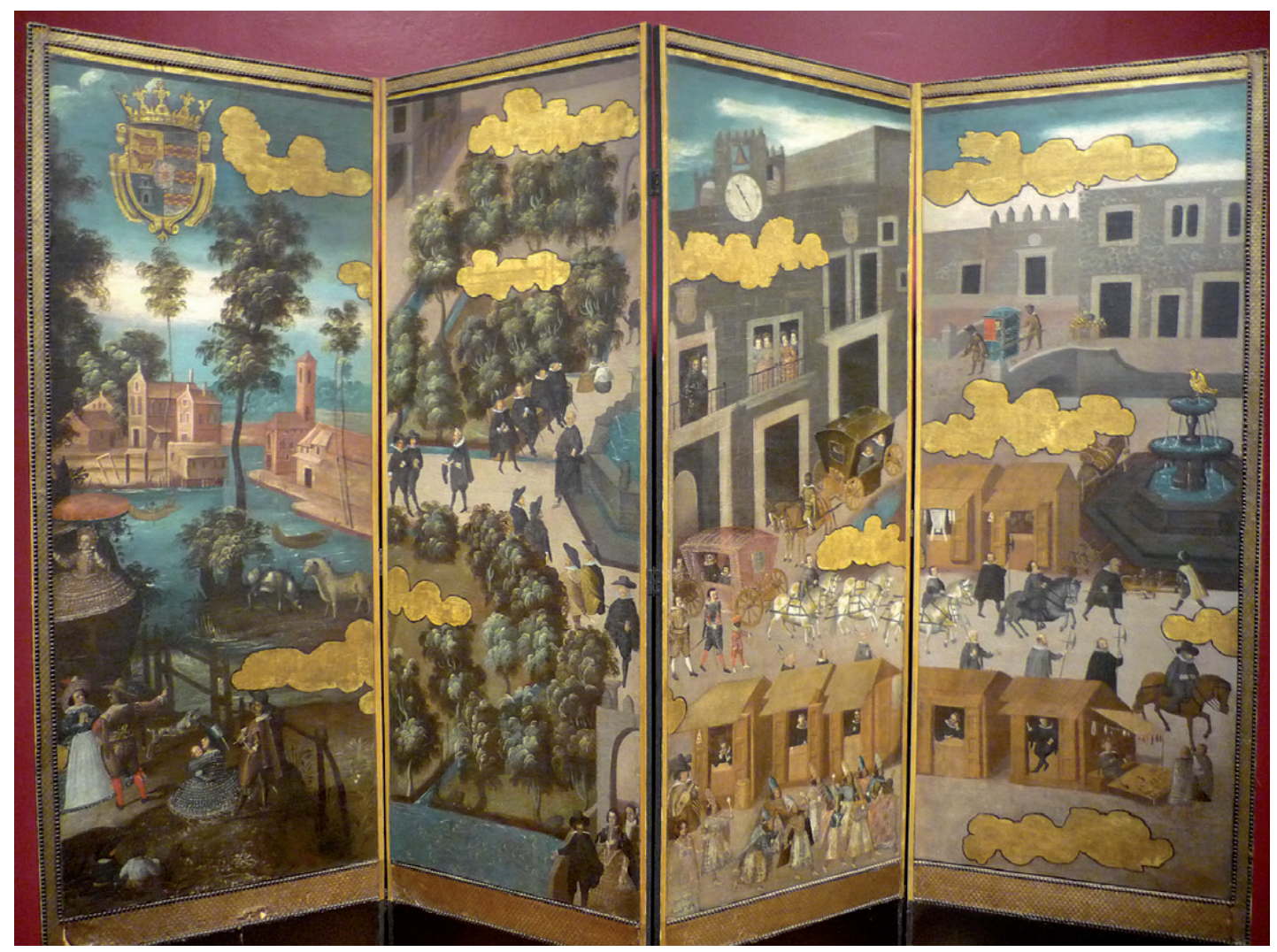

Fig. 1. Biombo con «Vista de la Plaza Mayor de la ciudad de México y del paseo de Iztacalco», colección Rivero Lake, México.

no respaldan esta teoría. La mayoría de ésta población se fijó en la costa del Pacífico como trabajadora en las haciendas de cacao y palma de coco y la que se dirigió a la ciudad de México se ocupó como comerciantes, barberos o plateros, siendo los esclavos destinados al servicio doméstico y a los obrajes textiles principalmente ${ }^{7}$.

Además, ninguno de los artistas identificados parece haber sido asiático. La mayoría de los biombos son obras anónimas, aun así varios de los ejemplares de lienzo pintado conservados hasta la fecha han podido atribuirse a pintores reconocidos como Juan Correa, Miguel Cabrera o José Joaquín Magón. En el caso de las pinturas con incrustaciones de madreperla, a los nombres ya conocidos de los hermanos González se van sumando otros que pudieron trabajar en la ciudad de México, Puebla o en Oaxaca, como Antonio de Santander, Pedro López de Calderón, Nicolás Correa, y Agustín del Pino ${ }^{8}$.

Tampoco los estudios técnicos y artísticos de las piezas parecen indicar una factura asiática. El hecho de que los análisis realizados a la serie de enconchados del museo de América de Madrid demuestren la existencia de un dibujo subyacente hecho con lápiz metálico, o que en las cenefas

\footnotetext{
${ }^{7}$ Oropeza, 2007. García-Abásolo, 2011: 117-145; 2012.

${ }^{8}$ La mayoría fueron también pintores de lienzos. Oropesa, 2013.
}

Arch. esp. arte, LXXXVIII, 350, ABRIL-JUNIO 2015, 173-188

ISSN: 0004-0428, eISSN: 1988-8511, doi: 10.3989/aearte.2015.11 
de biombos que imitan las formas del arte namban aparezcan tulipanes típicos del arte flamenco, indican que los autores de estos trabajos unieron la técnica de decoración oriental con la práctica pictórica europea ${ }^{9}$. Por lo demás, los biombos mexicanos no se elaboraron en papel o seda como muchos de los asiáticos, sino que introdujeron nuevos materiales como la piel, algunas telas o, sobre todo, el lienzo pintado al óleo. La madera laqueada pudo estar presente pero, como veremos más adelante, con características técnicas muy diferentes a las de los ejemplares chinos de exportación. Tampoco la simple presencia de motivos orientales en las composiciones puede utilizarse como prueba ya que, además de que los signos podrían imitarse con facilidad, el significado simbólico con el que se utilizaban en Nueva España era diferente al original.

Por lo tanto, sin excluir la posible intervención de chinos, japoneses o filipinos cristianizados e hispanizados en el virreinato, se podría pensar también en la labor de artistas novohispanos culturalmente mestizos. Estos artesanos se verían estimulados por una serie de circunstancias económicas y sociales propias del virreinato que favorecerían la consolidación de una manufactura de biombos mexicanos.

En primer lugar, la encomienda de estas piezas necesitaba articular una compleja red comercial de larga distancia. El envío de las instrucciones al artesano asiático, la elaboración del mueble y el transporte hasta su destino, conllevaba un tiempo considerable que podía verse frustrado si se producía algún problema durante el viaje. Al igual que sucedería en Europa, la necesidad de aumentar el acceso a las piezas animó el surgimiento de una producción de lacas a imitación de las que se importaban de Asia, pero también de otros objetos de lujo ${ }^{10}$.

Del mismo modo, no se puede olvidar la oportunidad económica que la demanda de este mueble brindaba a los artesanos locales. Al deshacerse de los gastos derivados del transporte y los intermediarios, los biombos mexicanos del siglo XVII podían ofrecer precios más baratos que los chinos o japoneses, la mayoría entre los 5 y los 30 pesos, y sólo en aquellos casos hechos "al remedo de maque" o de "maqué fingido" serían valorados entre los 30 y los 50 pesos, por debajo del coste medio de un biombo asiático conservado en buen estado durante esta centuria ${ }^{11}$.

Otro de los aspectos que resultó determinante fue el de adaptar las pinturas de las piezas al gusto y los intereses de sus compradores. De esta manera, podemos dividir la producción local en dos grandes grupos según fueran los temas elegidos para cubrir sus hojas. Por un lado, se reinterpretaron los motivos chinos y japoneses para combinarlos en un estilo nuevo que se adecuaba a la moda novohispana. Estos ejemplares, denominados en las fuentes como "achinados", "a la moda

\footnotetext{
${ }^{9}$ Rivás Díaz, 2002. Escalera y Rivás, 2002. Martínez del Río, 1994.

${ }^{10}$ En 1688 John Stalker y George Parker publicaron en Inglaterra un tratado de arte en el que afirmaban que la aparición en Europa de una oferta de lacas a imitación de las orientales permitiría obtener "conjuntos completos de mobiliario lacado cuando antes se deberían contentar con un biombo, un tocador o una taza". Stalker y Parker, 1971: 17.

${ }^{11}$ Por cuestiones de espacio sólo referiremos dos ejemplos que en las fuentes aparecen con el adjetivo de "mexicano": en 1680 el presbítero Nicolás de Vergara dejó a su muerte uno bien tratado, valorado en 30 pesos (AGN, Civil, vol. 1835, exp. 7, f.2v.); mientras que en 1694, Manuela Fernández de Velasco tenía otro del mismo tipo, en este caso maltratado, que fue apreciado en 10 pesos, junto a un ejemplar chino de 50 pesos (AGN, Bienes nacionales, vol. 445, exp. 4, f. 11r).

En los inventarios de algunos personajes es posible observar las diferencias de precio de los biombos mexicanos según fuesen los materiales y técnicas empleados. En 1714 Juana de Medina y Gutiérrez registró: "Un rodaestrado remedo de maque dorado que se compone de doce tablas de bara y cuarto de alto nuevo avaluado en 50 pesos", "otro rodaestrado pintura ordinaria que se compone de diez tablas pintado de montería avaluado en 20 pesos", "Un biobo de cama de doce tablas de un az, con una fábula avaluado en 20 pesos" (AGN, Civil, vol. 323, exp. 5, ff. 282v-283r).

Sobre el precio de los biombos asiáticos durante el siglo XVII: El capitán Andrés de Acosta tuvo dos que fueron rematados a su muerte en 1623 por 450 pesos (AGN, Civil, vol. 1998, exp. 3, f. 4r); en 1651 Gabriela de la Ribera legó a su muerte "dos biogos pequeños de China de estrado", maltratados, que se vendieron por 70 pesos (AGN, Civil, vol. 1720, exp. 3, f. 24v); mientras que los dos biombos de China del contador Miguel Jerónimo de Ballesteros fueron comprados en 1694 por 100 pesos cada uno (AGN, Civil, vol. 1569, exp. 2, f. 9v).
}

Arch. esp. arte, LXXXVIII, 350, ABRIL-JUNIO 2015, 173-188 ISSN: 0004-0428, eISSN: 1988-8511, doi: 10.3989/aearte.2015.11 
de China", o "al remedo de China", combinaban elementos de varias tradiciones artísticas para crear "ambientes orientales". Por otra parte, el deseo de utilizar nuevos temas relacionados con las inquietudes culturales de la floreciente élite novohispana, inició una escuela de biombos cuyas pinturas procedían de la tradición occidental. Una parte de los asuntos representados se apoyaba en los grabados llegados desde Europa, pero otra se integraba en el contexto novohispano. El hecho de que algunos temas elegidos fuesen tomados del pasado o las reivindicaciones locales, relacionan este tipo de piezas con el surgimiento de una nueva identidad criolla ${ }^{12}$.

En cuanto a en qué momento la influencia ejercida por las mercancías asiáticas llegadas en el galeón de Manila se materializó en una producción local de biombos, la discusión se circunscribe a la primera mitad del siglo XVII. Varios autores se disputan el hallazgo del primer ejemplar mexicano pero, en algunos casos, la pérdida de una perspectiva general les ha conducido a conclusiones erróneas. Sofía Sanabrais, en un artículo sobre la circulación mundial de estos objetos, se atribuye el descubrimiento. La investigadora sostiene que el biombo aparecido en el inventario de bienes de 1617 del virrey Luis de Velasco II es el primero de producción novohispana del que se tiene noticia. Afirma además que, teniendo en cuenta el tiempo de transporte desde México hasta España, el marqués debió adquirirlo antes de abandonar el virreinato en 1612 y sitúa en ese momento el inicio de la factura mexicana ${ }^{13}$.

No obstante, no estamos de acuerdo con esta conclusión. Sofía Sanabrais traduce la referencia a "un biombo grande de la yndia" contenida en el inventario de Luis Velasco por "a large biombo from the Indies", lo que le lleva a confundir la India oriental, que haría alusión al subcontinente asiático, con las Indias occidentales, denominación con la que se refería la documentación oficial castellana al continente americano. Por el contrario, si revisamos las fuentes españolas y portuguesas contemporáneas se llega a una conclusión diferente. En la península ibérica, muchos de los biombos que se definen como "de la India" se refieren en realidad a ejemplares asiáticos llegados a Europa de la mano de los portugueses. La equivocación posiblemente se debió al hecho de que los barcos del Estado da India solían parar en Goa de vuelta a Lisboa. Este mismo error se dio en numerosas ocasiones, como sucede en los inventarios portugueses con la denominada "porcelana de la India" que, en realidad, era de China. Apoyando esta teoría, en la "tasa de los precios" elaborada en Madrid en 1628, encontramos un apartado para las "Mercaderías de la India y Portugal". Aquí, entre diferentes muebles de lujo de China y Japón, se hacía referencia a los "Viobos grandes de la India" que llegaban por la ruta portuguesa con el Pacífico ${ }^{14}$. Dado que el inventario se hizo en Madrid, es lógico pensar que en realidad se refiriese a un biombo asiático.

Además, es necesario recordar que el shogun Iyesasu Tokugawa respondió a los presentes de la misión diplomática de Sebastián Vizcaino a Japón enviando a Luis de Velasco "cinco cajas de biombos y tres pares de armas"15. Cuando estos obsequios llegaron a Nueva España se encontraba como virrey el marqués de Guadalcazar, que los haría llegar a su antecesor. Así, en el barco en el que viajaba el embajador Hasekura a España figuraban cuatro cajones con "cosas del Japón y regalos d'esa tierra» para su entrega en Sevilla a Velasco, en ese momento presidente del Consejo de Indias. Es probable que entre estos regalos japoneses llegados en 1614 se encontrase el biombo

\footnotetext{
${ }^{12}$ Baena, 2007; Ocaña, 2008.

13 "Un biombo grande de la yndia que tiene ocho tablas y está bien tratado tasose en 800 reales (A large biombo from the Indies with eight leaves, in good condition, valued at 800 reales)" Inventario de los bienes que quedaron por muerte de don Luis de Velasco, marqués de Salina, Archivo Histórico de Protocolos de la ciudad de Madrid (AHPM), 2320, 21 de septiembre, 1617, 92r-93v.

Sanabrais, 2006: pp. 80 y 81.

${ }^{14}$ Aguiló, 1993: 436

${ }^{15}$ Copia de carta de Sebastián Vizcaino al marqués de Salinas de 20 de mayo de 1614 sobre altercado con fray Luis Sotelo, Archivo General de Indias (AGI), Filipinas, 1, N.151, 4, fol. 1.
}

Arch. esp. arte, LXXXVIII, 350, ABRIL-JUNIO 2015, 173-188

ISSN: 0004-0428, eISSN: 1988-8511, doi: 10.3989/aearte.2015.11 
al que se refiere Sofía Sanabrais ${ }^{16}$. Esta suposición se apoya en el hecho de que en las propiedades del antiguo virrey aparezcan precisamente cinco biombos entre los objetos de Japón y la India, además de seis "armas de la China", justo el mismo número de piezas del presente diplomático ${ }^{17}$.

Más confiable resulta la fecha que defiende la investigadora Berenice Ballesteros, quien localiza en el inventario de bienes de 1645 del comerciante mexicano, Lope de Osorio, un "beobo de la tierra, nuevo, de ocho lienzos con las Virtudes y Sentidos pintadas en él"18. Este ejemplar fue posiblemente contemporáneo del biombo Vista de la Plaza Mayor de la ciudad de México y laguna de Ixtacalco de la colección Rivero Lake. Dado que en su ángulo superior izquierdo aparece el escudo del marqués de Cadereyta, podemos suponer que se trata del mismo que hemos hallado entre las propiedades del que fuera virrey de la Nueva España, Lope Diez Aux de Armendariz y Saavedra. En su inventario de bienes realizado en Madrid en 1644, aparece "un biombo de dos varas y media de alto con ocho tablas que está pintado en el la plaza de México y algunas figuras" $" 19$. De las ocho hojas que es probable que tuviese, actualmente se conservan cuatro. Aun así, podemos contemplar representados los lugares más transitados por la aristocracia mexicana (la Alameda, Ixtacalco, y la plaza principal con el palacio) (fig. 1). Si tenemos en cuenta que el marqués de Cadereyta ejerció sus funciones entre 1635 y 1640, es posible deducir que para la década de los años treinta ya se producían biombos en Nueva España.

$\mathrm{Al}$ margen del debate sobre cuando surgiría el primer biombo mexicano, lo que demuestran las fuentes sin ningún tipo de dudas es que para la segunda mitad del siglo XVII ya estaba totalmente consolidada su elaboración y venta. En la centuria siguiente los biombos mexicanos alcanzarían un conjunto de población muy amplio, que abarcaba libreros, panaderos, mercaderes, inquisidores, funcionarios reales, médicos, mineros, regidores, clérigos, etc. ${ }^{20}$ Asimismo, la calidad y el volumen de esta manufactura les permitiría destinar una parte a la exportación, tanto a Europa como al resto de América $^{21}$.

Los biombos mexicanos tuvieron una gran variedad en función del material con el que se elaboraron, existiendo de madera pintada y laqueada, de lienzo pintado al óleo, de piel, de tela, o de pinturas con incrustaciones de madreperla. Si relacionamos la manufactura de éste último tipo de biombos con las tablas realizadas con esta misma técnica, algunas similitudes formales abren la puerta a nuevas interpretaciones sobre cuáles pudieron ser los referentes en los que se fijaron los artistas novohispanos.

Tradicionalmente se ha hecho hincapié en la conexión que tuvieron los enconchados con las lacas namban, sin embargo, éstas últimas fueron anteriores y técnicamente diferentes ${ }^{22}$. Sin desmerecer este antecedente, debe valorarse también la influencia que pudo ejercer la constante llegada de biombos asiáticos, algunos con materiales muy parecidos. Así por ejemplo, en el albaceazgo del antiguo gobernador de Filipinas, Fausto Cruzat y Góngora, hecho en México en 1706

\footnotetext{
${ }^{16}$ Gil, 1991: 389.

17 "Un biombo grande de la India, tiene ocho tablas y está bien tratado todo tasose en ochocientos reales Otro biovo de otras ocho tablas tan bien tratado como el de arriba en otros ochocientos reales

Otro biovo no tan bueno como los de arriba que tiene otras ocho tablas tasose en trescientos cincuenta reales

Dos biobos pequeños de a seis tablas cada uno tasáronse en cuarenta ducados ambos" Inventario de los bienes que quedaron por muerte de don Luis de Velasco, marqués de Salina, AHPM, 2320, 21 de septiembre 1617, 89r y 92r-93v.

${ }_{18}$ Ballesteros, 2008: 83.

19 Inventario de bienes de Lope Diez Aux de Armendariz y Saavedra, Marqués de Cadereita, 16 de febrero de 1644. AHPM, 6219, f.804r.

${ }^{20}$ Baena, 2013. Curiel, 1999.

${ }^{21}$ Baena, 2012 y Sanabrais, 2006.

${ }^{22}$ Sonia Ocaña destaca la relación formal de los marcos de los enconchados con el arte namban, aunque deja claras las diferencias técnicas con las lacas japonesas. Ocaña, 2008. Ver también: Vargas Lugo, 1994; Dujovne, 1984.
}

Arch. esp. arte, LXXXVIII, 350, ABRIL-JUNIO 2015, 173-188 ISSN: 0004-0428, eISSN: 1988-8511, doi: 10.3989/aearte.2015.11 


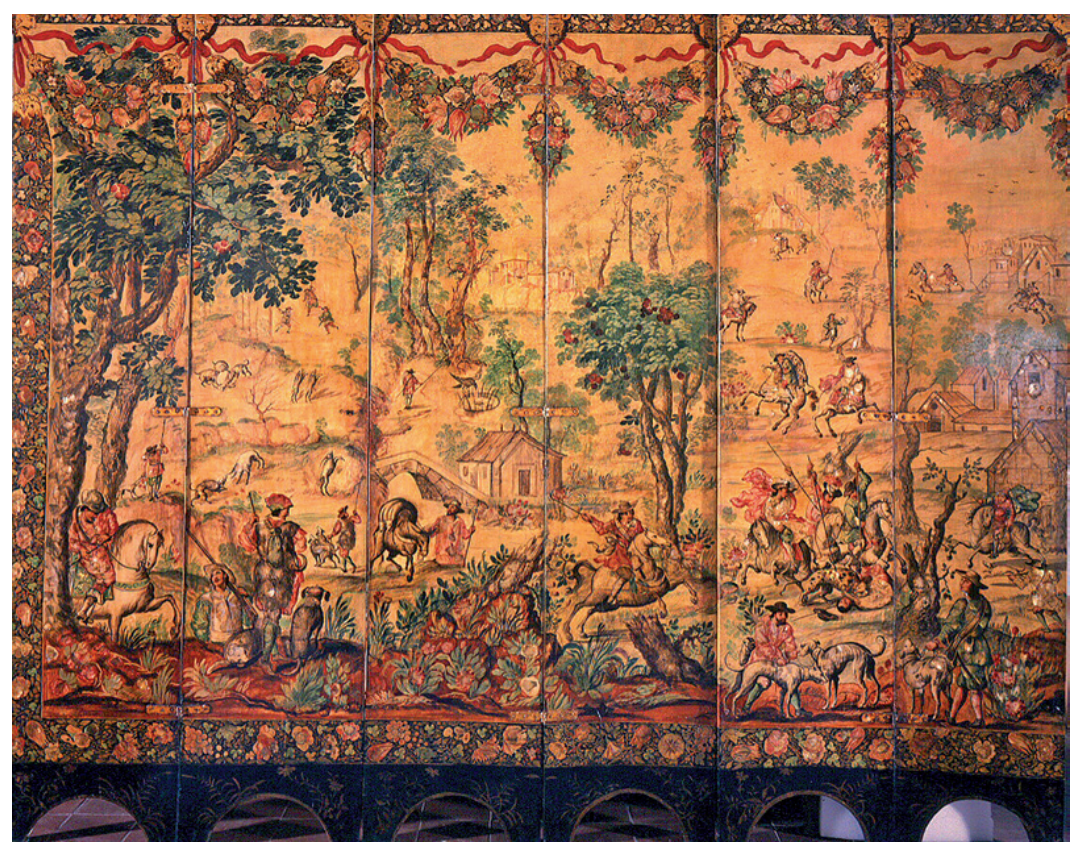

Fig. 2. Familia González. Folding Screen with the Siege of Belgrade (front) and Hunting Scene (reverse), ca.1697-1701. Oil on wood, inlaid with mother-of-pearl, 90 1/2 x $1085 / 8$ in., 183.5 lb. (229.9 x $275.8 \mathrm{~cm}, 83.24$ $\mathrm{kg}$ ). Brooklyn Museum, Gift of Lilla Brown in memory of her husband, John W. Brown, by exchange, 2012.21.

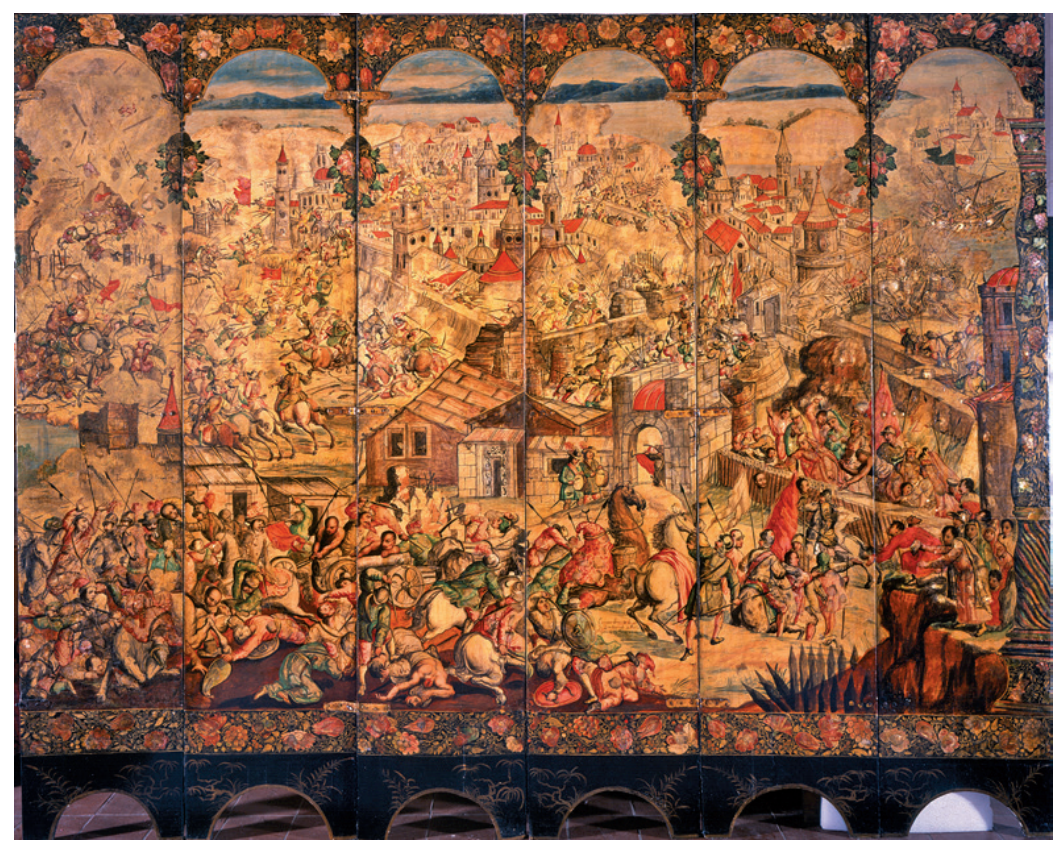

Fig. 3. Familia González. Folding Screen with the Siege of Belgrade (front) and Hunting Scene (reverse), ca.1697-1701. Oil on wood, inlaid with mother-of-pearl, $901 / 2 \times 1085 / 8$ in., 183.5 lb. $(229.9 \times 275.8 \mathrm{~cm}, 83.24$ $\mathrm{kg}$ ). Brooklyn Museum, Gift of Lilla Brown in memory of her husband, John W. Brown, by exchange, 2012.21.

Arch. esp. arte, LXXXVIII, 350, ABRIL-JUNIO 2015, 173-188

ISSN: 0004-0428, eISSN: 1988-8511, doi: 10.3989/aearte.2015.11 
aparecen seis biombos de maque de Japón y madre perla, uno de montería y otro de pájaros, además de cuatro de maque y piedra ágata ${ }^{23}$. Además, los biombos chinos de Coromandel, muchos de los cuales se transportaron hasta América, eran realizados con madera pintada sobre la que se añadía una capa de laca y que, en algunas ocasiones, podían llevar incrustaciones de marfil, concha o carey ${ }^{24}$. Si bien las técnicas empleadas también fueron diferentes, se trató de modelos que pudieron inspirar a los pintores de laca novohispanos.

La relación entre enconchados y biombos debió de darse de manera natural, ya que el formato en tabla de los primeros se adaptaba fácilmente al de las hojas de los segundos. De esta manera, algunas de estas tablas fueron transformadas en biombos después de elaborarse, como sucede con las series de las batallas de Alejandro de Farnesio, de la colección Rivero Lake, y de la Conquista de México, del museo nacional del virreinato en Tepotzolán ${ }^{25}$.

Tanto tablas como biombos compartieron el gusto por representar los mismos asuntos (la conquista, el sitio de la ciudad de Viena, o la historia de Don Quijote) y algunos tipos de ornamentación, por lo que no resulta extraño que llegaran a unirse. Así, se ha conservado al menos un biombo que fue pensado desde su origen para ser realizado con pintura de concha nácar. Este ejemplar perteneció al Conde de Moctezuma a finales del siglo XVII, representando el sitio de la ciudad de Viena por un lado y una escena de montería por el otro ${ }^{26}$. Mientras que en las tablas la composición se realizaba de manera autónoma y se rodeaba de una cenefa decorativa que la delimitaba, en el biombo conservado la escena tenía continuidad entre todas las hojas y la ornamentación se aplicaba a la pieza en su conjunto. La obra es anónima pero la investigadora Sonia Ocaña ha señalado que una de las figuras que aparece representada en la batalla de Viena "parece haber utilizado el mismo calco que una figura que aparece en la tabla nueve de la Conquista de México", firmada por Miguel González, lo cual sugeriría que ambos trabajos tendrían el mismo autor ${ }^{27}$. De ser cierto, tendríamos una prueba del tránsito de artistas entre ambos tipos de piezas (figs. 2 y 3 ).

\section{Posibles centros de manufactura de biombos en Nueva España}

Una vez fijada una cronología provisional para el origen de los primeros biombos mexicanos y de reflexionar sobre las posibles causas que motivaron su nacimiento, la siguiente cuestión es ubicar dónde pudieron realizarse. Hasta el momento existen pocos trabajos que se preocupen por determinar el lugar o lugares en que se elaboraron los biombos. El silencio de la historiografía especializada en relación a este aspecto puede deberse tanto a que la mayoría de estas piezas son anónimas como a que no existió un gremio de artesanos que se ocupase en exclusiva de su factura. Es probable que dependiendo del tipo de biombo (de madera laqueada, de tela, de piel o de lienzo pintado al óleo) pudieran participar varios artesanos diferentes (carpinteros, curtidores, pintores, entalladores, etc.). Tampoco los documentos de la época proporcionan mucha información sobre el origen de las piezas, más allá de indicar que en el Parian de la plaza mayor de México se vendían

${ }^{23}$ Inventario de bienes de Fausto Cruzat y Góngora, 1706, Archivo General de la Nación de la ciudad de México (AGN), Civil, vol. 114, exp. 1, ff. 53r, 53v y 60v.

${ }^{24}$ Kesel, 2002.

${ }^{25}$ Se ha apuntado la posibilidad de que la reina Mariana de Neoburgo tuviese dos biombos "enconchados" que legaría años después a su sobrina Isabel de Farnesio, ya que en su inventario de bienes de 1745 se refieren dos biombos de charol y nácar con pintura fina heredados de su tía. Véase Lavalle Cobo, 2003.

${ }^{26}$ El biombo se encuentra dividido en dos partes, una conservada en el Museo nacional del Virreinato en Tepotzotlán y la otra en el museo de Brooklyn. Sobre "la conquista de Viena" existen también unas tablas de enconchado realizadas por Juan González en 1682, conservadas en una colección particular en las islas Canarias. García Sáinz, 1993-1994: 26-39.

27 Ocaña, 2005, p. 205. 
los que llegaban en el galeón de Manila. Siendo esto así, resulta imprescindible encontrar nuevas fuentes que arrojen luz sobre esta cuestión y relacionar el surgimiento de esta producción con otras con las que pudiera compartir materiales, técnicas o motivos.

Si se presta atención a las crónicas que nos hablan sobre las artesanías locales en Nueva España, debemos detenernos en primer lugar en los objetos de madera y laca. Gracias a cronistas como Juan Suárez de Peralta, fray Bartolomé de las Casas o fray Pablo Beaumont, sabemos que en las regiones de Michoacán y Guerrero existió un tipo de barniz antes de la llegada de los españoles. En el momento de evangelizar la zona, Vasco de Quiroga abogó por mantener los oficios tradicionales y adaptarlos a las nuevas necesidades, ayudando así a perpetuar el trabajo del barniz. De esta manera, la investigación realizada por Francisco León, primero, y por José Guadalupe o Teresa Castelló, después, demostraron que las lacas mexicanas del periodo virreinal no derivaban de las asiáticas sino de las técnicas prehispánicas conservadas ${ }^{28}$. El barniz utilizado en América tenía como base un compuesto formado por la grasa animal extraída del cuerpo de un insecto, mientras que el maque asiático era una resina de origen vegetal que cubría los objetos con una película espesa que le otorgaba el brillo.

En el siglo XVI, el barniz prehispánico se combinó con los modelos europeos de muebles, dotándose de originalidad a través de las pinturas con que se decoraban. El fraile Matías de Escobar resumió este proceso al recordar cómo un siglo antes, "viendo los misioneros el trabajo que los indios ejecutaban en jícaras y calabazas, les dieron hierros para que trabajaran la madera y pudieran hacer andas de santos y grandes bateas", de esta forma, "añadirían los nativos sus maques y sus pinturas y hacían singular su obra pues a un mismo tiempo lucía la española traza, vestida de ropaje indiano" 29 . A mediados del siglo XVII, fray Alonso de Rea había descrito en su crónica de la provincia de Michoacán las excelentes propiedades de la pintura de Peribán, afirmando que con ella "hacen excelentes escritorios, cajas, baúles y cestones, tecomates y vasos peregrinos, bateas, jícaras y bufetes, con otras muchas curiosidades" ${ }^{\prime 30}$. Si esto sucedió con los modelos europeos, nada impide pensar que lo mismo pudiera hacerse con los objetos de moda que llegaban desde la otra parte del mundo. En este sentido, la presencia temprana y familiar de biombos en Michoacán queda demostrada por su representación en una de las pinturas murales que rodeaban el claustro del ex convento franciscano de Santa Ana en Tzintzuntzan, posiblemente del siglo XVII (fig. 4).

Además, los inventarios de bienes prueban que existió un artesanado de muebles "pintados" en la región desde inicios del siglo XVII, alcanzando un prestigio y un volumen tan importantes como para sobrepasar el abastecimiento del mercado local desde fechas tempranas. Así por ejemplo, en 1622 Rodrigo Velázquez de Cárdenas, alcalde ordinario de la ciudad de México, declaraba tener un "escritorio de Michoacán pintado" y "otro colorado pintado de Michoacán" ${ }^{31}$; Diego Medrano, oidor de la audiencia de Guadalajara, hacía lo propio con "dos bufetes grandes pintados de Michoacán"32; el oficial real Sebastián de Castilla Calderón aseguraba tener en su residencia de la ciudad de México "un escritorio de Michoacán pintado"333 mientras que el capitán Pedro de Espinosa, vecino de Colima, contaba con "dos cajas de pintura de Michoacán fina"34.

${ }^{28}$ León, 1939. Castelló Iturbide, 1972, 2: 33-82; 1981. Guadalupe Zuno, 1952.

${ }^{29}$ Escobar, 1924: 49.

${ }^{30}$ Rea, Alonso de "Crónica de la Orden de N. Seráfico P. San Francisco, provincia de San Pedro y San Pablo de Michoacán de la Nueva España” (1639-1643) citado por León, 1984: 21.

${ }^{31}$ Inventario de bienes: Velázquez de Cárdenas, Rodrigo, 13 de agosto de 1622, AGI, México, 259, N.271, ff. 777v y $778 \mathrm{r}$.

${ }^{32}$ Inventario de bienes: Medrano, Diego de, 5 de agosto de 1622, AGI, México, 262, N.154, f.411r.

${ }^{33}$ Inventario de bienes: Castilla Calderón, Sebastián, 19 de julio de 1622, AGI, México, 261, N.45, f.118r

${ }^{34}$ Inventario de bienes: Espinosa, Pedro, 17 de agosto de 1622, AGI, México, 262, N.89, f.246v.

Arch. esp. arte, LXXXVIII, 350, ABRIL-JUNIO 2015, 173-188

ISSN: 0004-0428, eISSN: 1988-8511, doi: 10.3989/aearte.2015.11 


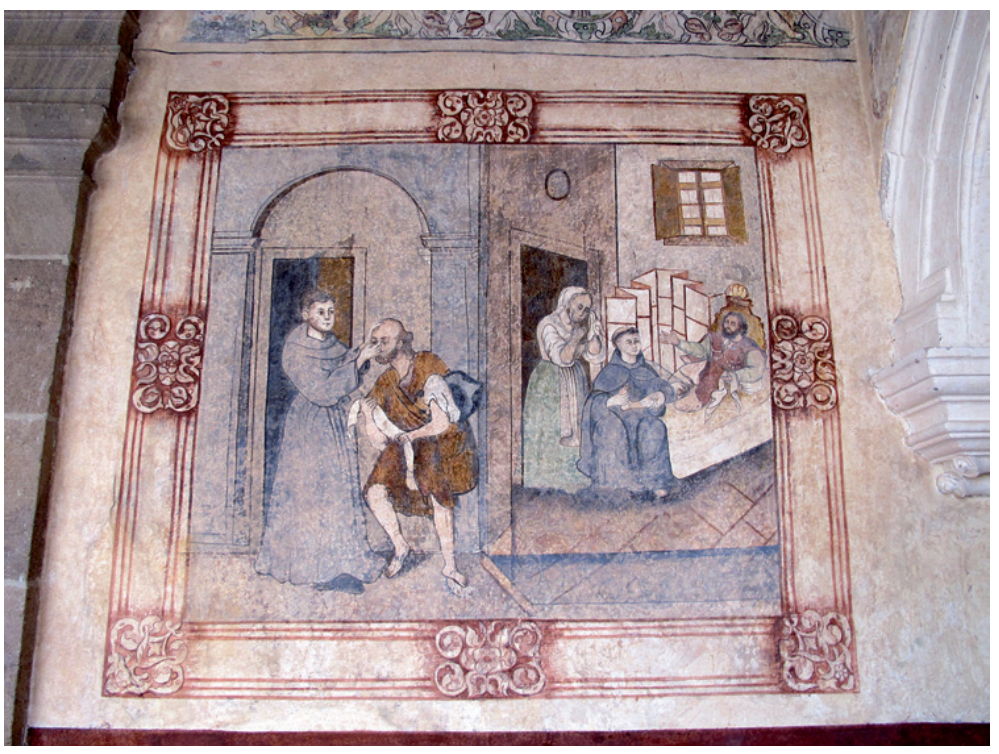

Fig. 4. Pintura mural del claustro del ex convento franciscano de Santa Ana en Tzintzuntzan (Michoacán).

Ya en el siglo XVIII, Francisco de Ajofrín, en su Diario del viaje a la Nueva España, se refería a Pátzcuaro como un centro ya consolidado en la elaboración de muebles lacados y con formas "achinadas": "[los indios] Ya han olvidado este ejercicio [la pintura de plumas], pero no el de pintar bateas maqueadas o acharoladas. Hoy florece un célebre pintor, indio noble, llamado Don José Manuel de la Cerda, que ha perfeccionado mucho esta facultad, de suerte que excede en primor y lustre a las maques de la China"35

Si bien tenemos documentados para la misma época producciones relevantes de muebles en la sierra de Oaxaca, en Campeche, en Puebla o en Taxcala, lo que destaca en Michoacán es el uso de la pintura y la laca como elementos característicos. En cuanto a los motivos representados, en Quiroga, Olinalá y Chiapa de Corzo abundó el uso de las formas naturales, mientras que en Patzcuaro existió una gran variedad iconográfica de influencia tanto occidental como oriental, que pudo trasladarse también a los biombos ${ }^{36}$. Seguramente, la presencia en esta última ciudad de una Aduana Real por la que pasaban las mercancías llegadas desde Filipinas contribuyó al conocimiento y difusión de las formas y signos asiáticos.

La idea de que la manufactura de muebles "achinados" y la de biombos de madera pudieron estar relacionadas se basa en las similitudes encontradas tanto en los motivos representados como en la técnica aplicada para su elaboración. Así, es interesante comprobar que la decoración de muchas de las bateas y muebles barnizados que se han conservado hasta nuestros días comparten con los biombos laqueados, tanto la misma inspiración oriental en los paisajes (sauces, pagodas, aves...), como algunos de los temas elegidos (composiciones "achinadas", historias mitológicas, escenas cotidianas y de género, pasajes del Quijote, etc.). Estos puntos en común apoyan la teoría de que estas manufacturas pudieron tener una misma matriz ${ }^{37}$. El parecido existente entre la es-

\footnotetext{
${ }^{35}$ Ajofrín, Francisco de: Diario del viaje a la Nueva España, México, Sep. Cultura, 1986, p. 97.

${ }^{36}$ Pérez Carrillo, 1987; 1997. Castelló Iturbide, 1972. Aguiló, 2008.

${ }^{37}$ El trabajo de Sonia Pérez Carrillo, aunque muchas de sus tesis hayan sido superadas, continúa siendo un referente en la explicación y catalogación de las lacas conservadas. Pérez Carrillo, 1990.
}

Arch. esp. arte, LXXXVIII, 350, ABRIL-JUNIO 2015, 173-188 ISSN: 0004-0428, eISSN: 1988-8511, doi: 10.3989/aearte.2015.11 
cribanía conservada en el Museo Regional Cuauhnáhuac (Cuernavaca) o el armario del Museo Franz Mayer, ambos michoacanos, con los biombos achinados conservados en las colecciones Franz Mayer y Alvear Zubiría, es evidente (figs. 5 y 6). En todos estos casos coincide el gusto por los fondos rojos para encuadrar composiciones que imitaban el estilo "oriental", la presencia destacada de animales en el primer plano (pájaros, patos...), la mezcla de edificios novohispanos con pagodas, o la aparición de personajes asiáticos. Asimismo, las piezas decoradas con figuras doradas evocan a las lacas de exportación de Cantón.

Si nos referimos a los biombos pintados sobre tela, actualmente se conserva uno realizado en Pátzcuaro en el siglo XVIII que también comparte características formales con las lacas de la región $^{38}$. La manera en la que se representan aves y mariposas y, nuevamente, el fondo rojo, recuerdan los muebles achinados de Michoacán, aunque escenificase un tema típicamente europeo, la alegoría del buen gobierno y la entrada de un rey.

Por otro lado, es necesario recordar

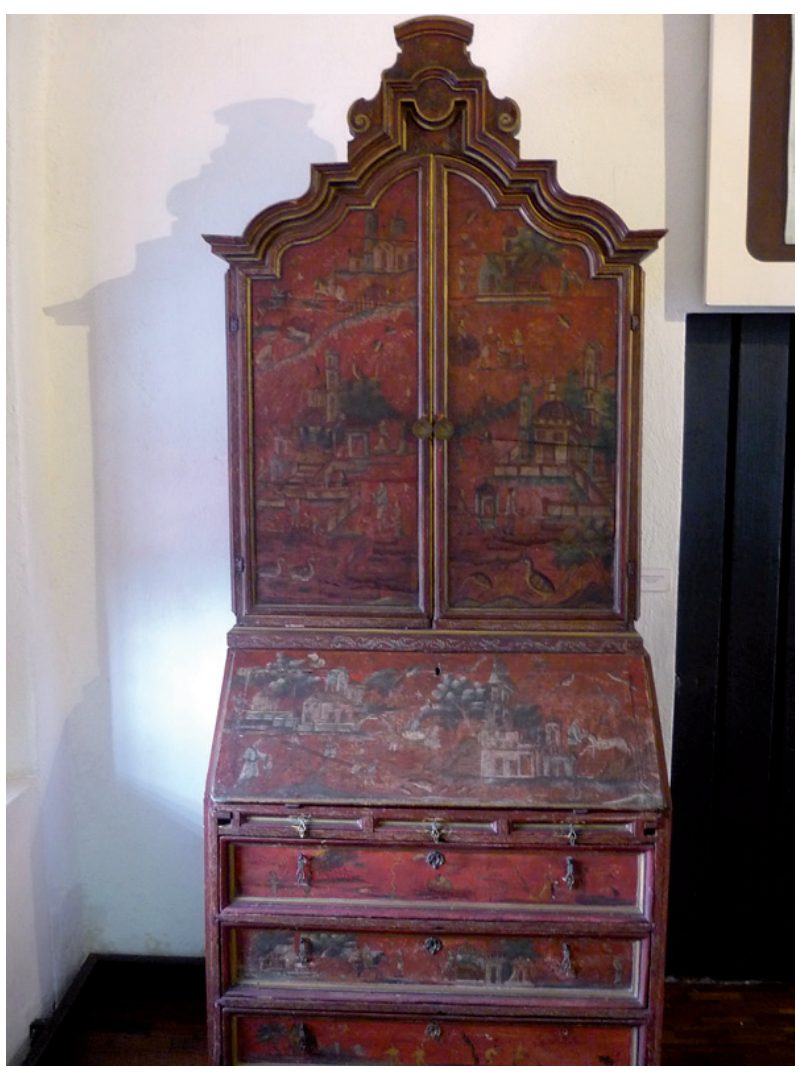

Fig. 5. Escribanía michoacana, madera laqueada, siglo XVIII, Museo Regional Cuauhnáhuac (Palacio de Cortés), México. que Michoacán no fue el único centro productor de muebles en Nueva España y que hubo otras zonas con capacidad para abordar este cometido. Campeche también tuvo desde inicios del siglo XVII una manufactura de gran envergadura y reconocimiento internacional, exportando muebles tanto al resto del virreinato como a la Península. En esta zona abundaban las tortugas y la concha nácar que, junto con el hueso, eran aplicadas sobre maderas de calidad como el ébano o la caoba importada de la Habana ${ }^{40}$. El hecho de que en 1684 Santiago de Curuzelaegui, comprador de oro y plata de la ciudad de Sevilla, tuviera un "biombo de la Nueva España" junto a "dos baules campechanos pintados" y "una papelera de Campeche", podría inducir a pensar que el primero fue enviado desde el mismo lugar que el resto ${ }^{41}$. Sin embargo, deberán esperarse nuevas investigaciones que profundicen en este asunto.

\footnotetext{
${ }^{38}$ Este biombo se exhibió en la exposición "El mueble mexicano" en 1983-1984 organizada por Fomento Cultural de Banamex, A. C. y dirigida por Fernando Gamboa, fue publicado en Aguilera García, 1985.

${ }^{39}$ Granados, 2000, 2: 647-669; 2002.

40 Martínez del Rio, 1985.

${ }^{41}$ Inventario de bienes de Santiago de Curuzelaegui, AHPS, Lib. 10287, año 1684, ff. 1298r-1329r.
}

Arch. esp. arte, LXXXVIII, 350, ABRIL-JUNIO 2015, 173-188

ISSN: 0004-0428, eISSN: 1988-8511, doi: 10.3989/aearte.2015.11 


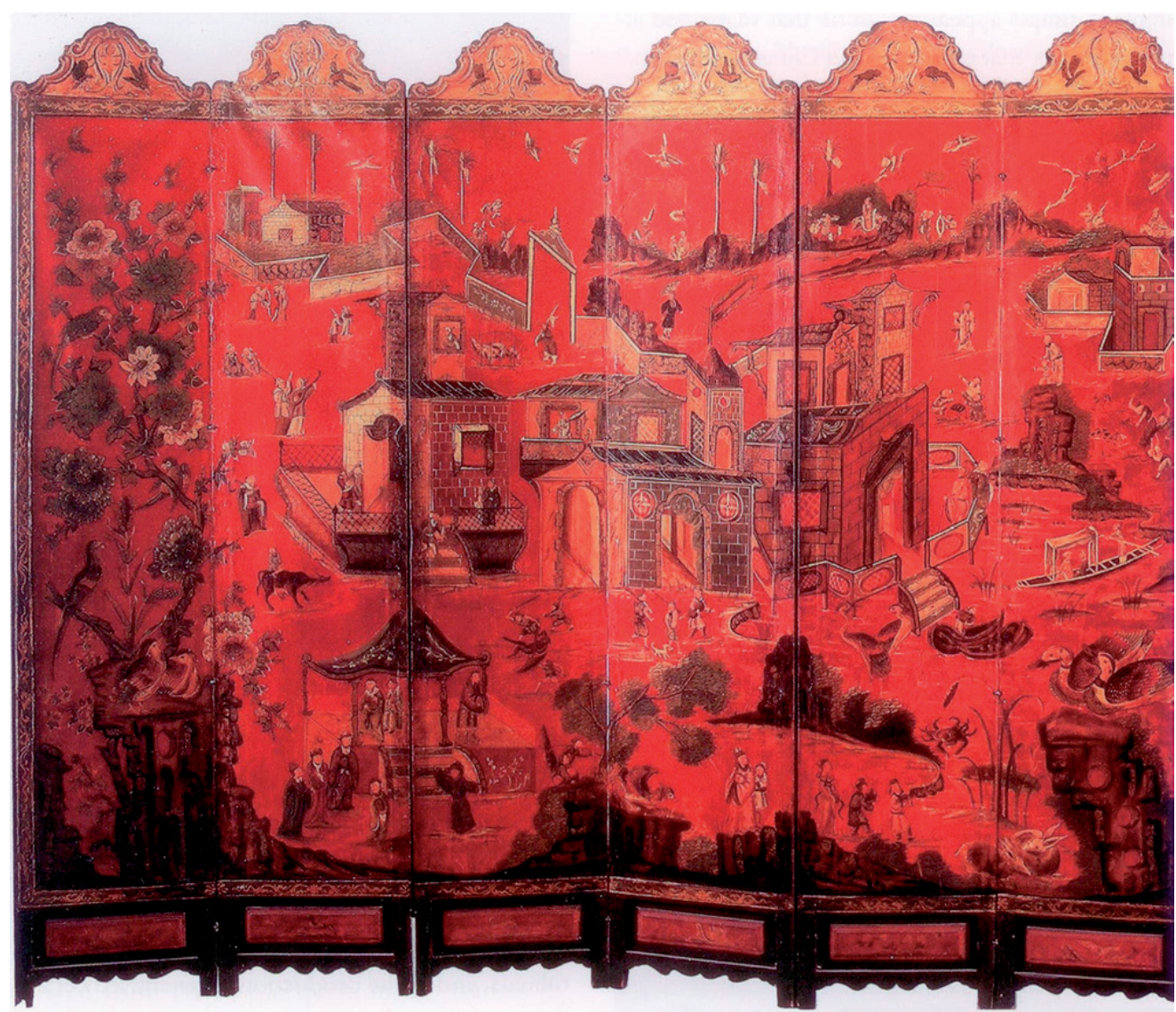

Fig. 6. Biombo achinado, Nueva España, siglo XVIII, Museo Franz Mayer, México. (Imagen en: Pierce, Donna y Otsuka, Ronald, Asia \& Spanish America, trans-pacific artistic and cultural exchange, 1500-1850, Denver, Simposium series, Denver Art Museum, 2006, p. 30).

La ciudad de Puebla y sus alrededores conformaron uno de los grandes centros manufactureros de la Nueva España, aglutinando varios tipos de artesanado. Aquí floreció la taracea o marquetería de maderas finas, caracterizada sobre todo por decoraciones foliáceas y rosetones, pero también con motivos figurativos basados en grabados flamencos ${ }^{42}$. Se trataba de muebles de gran calidad, muchos de los cuales tenían incrustaciones de carey y se iban adaptando a las modas europeas. Al mismo tiempo, desde finales del siglo XVI la loza de esta zona aunaría la tradición castellana con los modelos y los motivos venidos de Asia ${ }^{43}$. De esta manera, no es extraño encontrar pintadas sobre su superficie, plantas, aves o tipos físicos y vestimentas que remiten a la influencia de la porcelana.

${ }^{42}$ En el museo Franz Mayer se conserva un armario ropero hecho en Puebla que está decorado con medallones de figuras mitológicas basadas en estampas flamencas. Procede de la sacristía del oratorio de San Felipe Neri (ciudad de México). Ver: Pérez de Salazar, 2009.

43 Aguirre Anaya, 1997. Connors McQuade, 2007.

Arch. esp. arte, LXXXVIII, 350, ABRIL-JUNIO 2015, 173-188 ISSN: 0004-0428, eISSN: 1988-8511, doi: 10.3989/aearte.2015.11 
Ya en el siglo XVIII, Francisco de Ajofrín, al ocuparse de Puebla, se refirió a los "vistosos lienzos pintados a imitación de la China" que se hacían en la ciudad ${ }^{44}$. Esta referencia sugiere que los artesanos poblanos ya habían asimilado las formas orientales y las aplicaban no sólo en su famosa loza, sino que también pudieron hacerlo sobre otras superficies. No sabemos con seguridad si entre estas se encontraron los biombos "achinados", pero una parte de los ejemplares mexicanos eran realizados con lienzo pintado al óleo con el mismo tipo de motivos, algunos de los cuales llegaron a imitar el acabado brillante de la laca y los fondos rojos.

En Guatemala se desarrolló también una producción importante de muebles de lujo elaborados con incrustaciones de materiales preciosos (marfil, hueso, concha nácar, maqué), entre los que se contaron los biombos ${ }^{45}$. La calidad de estos trabajos fue reconocida internacionalmente y muchos fueron exportados a Europa y América. El conde de Monteblanco, por ejemplo, tuvo en Lima en 1765 un biombo de cama guatemalteco "embutido en concha de perla en campo de carey con una tarja cada hoja, con sus fabulas de la China, de buena pintura $\rangle^{46}$. Esta pieza fue tasada en 1200 pesos, una fortuna para la época, que superaba el precio de cualquier otro ejemplar del que tengamos noticia, y demuestra hasta qué punto se extendió en el continente una producción "achinada" paralela a la chinoiserie europea.

Por último, si se presta atención a algunos de los temas representados en los biombos que clasificamos como de tradición occidental podemos obtener pistas de donde pudieron ser realizados. Fueron comunes aquellos que representaban escenas de la ciudad de México y sus alrededores. Sólo en un caso hemos localizado la referencia a un lugar diferente, se trata de un biombo de badana en el que aparecía "El Parral", seguramente como recuerdo del paso de su dueño por esta ciudad minera ${ }^{47}$.

Así, fue habitual pintar el paseo de la Viga, que unía la Merced con Xochimilco, o los pueblos de Ixtacalco, Jamaica, o Santa Anita, que se encontraban de camino. En el biombo de la colección Buch Molina, por ejemplo, encontramos una descripción pormenorizadas de las actividades de ocio que se desarrollaban en estos paseos, de sus canoas adornadas con flores y sus criollas tocando instrumentos musicales, de los indígenas vendiendo alimentos, y de los paisajes de cada lugar (canales, puentes, edificios...). Por lo tanto, dado el conocimiento detallado que muestran estas pinturas de los espacios y sus actividades cotidianas, y por no haberse identificado ninguna fuente en la que se basaran los artistas, parece lógico pensar que éstos conocieron el medio y estaban familiarizados con la vida social de la capital. Siendo esto así, pudieron tener sus talleres en la propia ciudad de México o en sus inmediaciones.

Uno de estos lugares cercanos a la capital fue Xochimilco, que tuvo una producción de muebles y de donde es la única referencia explícita que hemos encontrado a la presencia de un individuo dedicado a la fabricación de biombos. Se trata de Ventura del Carmen Totozinco, quien asesinó con un "instrumento propio de los biomberos conocido por rallador" a otro hombre con el que se disputaba los amores de Lorenza Tibuncia ${ }^{48}$. El reo declaró, con la ayuda de un intérprete, ser indio soltero, vecino de Xochimilco y de oficio carpintero. A pesar de que los hechos

${ }^{44}$ Ajofrín, 1986: 55.

45 Nueva España exportó numerosos muebles y biombos a Sudamérica. Baena, 2012.

${ }^{46}$ Tasación que yo José de Zúñiga hago como inteligente a pedimento del señor Conde de Monteblanco de las papeleras, escritorios y otras piezas curiosas que se hallan en la casa de su morada trabajadas en la ciudad de Guatemala, Archivo General de Lima, Protocolos notariales, 83 escr. Orencio Ascarrunz, 1765, ff.1034r-1035v.

${ }^{47}$ El dueño de este biombo fue Martín de Valencia y Zavalza, propietario de una hacienda y una mina en la jurisdicción de Quaila de Amilpas. AGN, Civil, vol. 735, exp. 14, ff. 27v y 31r.

${ }^{48}$ En ese mismo expediente se afirma que la herramienta "sirve para hacer biogos o rallar la armazón de estos". Expediente contra Ventura del Carmen Totozinco por la muerte de Juan Evangelista Tlacuapa, 1801, AGN, Instituciones Coloniales, Real Audiencia, Criminal (037), Contenedor 123, vol. 236, Exp. 21, ff. 137-148.

Arch. esp. arte, LXXXVIII, 350, ABRIL-JUNIO 2015, 173-188

ISSN: 0004-0428, eISSN: 1988-8511, doi: 10.3989/aearte.2015.11 
referidos son de 1801, la fuente apoya la teoría de que en esta localidad existía una manufactura de biombos asociada a la de muebles.

Finalmente, ya apuntamos que pintores como Juan Correa, Miguel Cabrera o José Joaquín Magón no tuvieron problemas en decorar al óleo los lienzos de los biombos. Igualmente, conviene recordar que los biombos eran incluidos en los inventarios dentro de las pinturas y tasados por pintores. Por lo tanto, si se asocia la creación de ambos objetos, se deben señalar los talleres de pintura como posibles centros productores. En este caso, los dos grandes polos de producción pictórica del virreinato fueron la ciudad de México y Puebla, que como mínimo podrían cubrir su propia demanda de biombos. A tenor de los temas elegidos, este tipo de piezas permitirían a los pintores dejar a un lado los abundantes asuntos religiosos para ocuparse de los profanos.

\section{Consideraciones finales}

Muchas cuestiones quedan abiertas en relación al origen y desarrollo de la manufactura mexicana de biombos en Nueva España, aun así, es posible sostener ciertas ideas. Hasta el momento, no se puede asegurar que el trabajo de estas obras de arte fuera responsabilidad de artesanos asiáticos emigrados, pero sí que las condiciones particulares del virreinato a finales del siglo XVI e inicios del XVII influyeron en que brotase y creciese con fuerza. La situación privilegiada en el comercio con Asía, la existencia de mano de obra capaz de adaptarse a nuevos retos, o la demanda de objetos de lujo por parte de los grupos enriquecidos, son algunas de las causas que explican ésta innovación.

Los biombos mexicanos más antiguos localizados sitúan a la década de 1630 como posible cronología para el surgimiento de esta manufactura. Se trata de una fecha muy anterior a la de los primeros ejemplares europeos o del resto de América. Por lo tanto, Nueva España fue pionera en la reinterpretación de este mueble, tanto en los materiales utilizados como en los temas escogidos para su decoración, y pudo influir en las manufacturas posteriores.

Los biombos formaron parte de un grupo de manufacturas locales (tejidos, cerámicas, enconchados, bateas, muebles...) que compartieron repertorios ornamentales de inspiración asiática, pero que además coincidieron en su predilección por algunos temas de tradición occidental. La proximidad entre las llamadas "artes decorativas" hizo que en ocasiones los autores fueran los mismos, como demuestra el biombo realizado con la técnica del enconchado. En el caso de los ejemplares de óleo sobre tela, las fronteras con la pintura de cuadros se difuminan, ya que los artistas transitaron entre ambos tipos de piezas. Es probable que lo mismo sucediese con los artesanos responsables por pintar y barnizar tanto muebles o bateas como biombos de madera.

No es posible saber con certeza en qué lugar del virreinato se elaboraron primero los biombos. Las fuentes documentales y las piezas conservadas demuestran que hubo una gran variedad, tanto por los materiales y las técnicas empleados como por los temas representados sobre sus hojas. La información recopilada hasta el momento apunta a que probablemente existieran varios centros productores al mismo tiempo, variando en función del tipo. En cualquier caso, su manufactura debió alcanzar un volumen muy importante si tenemos en cuenta que además de cubrir la demanda interna se destinaron a la exportación.

Por último, el éxito de los biombos mexicanos en el siglo XVIII nos lleva a plantearnos nuevas cuestiones ¿Cómo fue la evolución de estos muebles? ¿Qué cambios hubo en su uso y en su significado? ¿Quiénes fueron los responsables de cubrir la demanda? ¿Cuándo y cómo se dio el paso de exportarlos hacia el resto del continente? o ¿Cuál fue la historia social de estas obras de arte? Todas estas preguntas deberán ser respondidas en el futuro por los especialistas. Por el momento, el único biombero localizado era un indígena de Xochimilco que no era capaz de expresarse correctamente en español, un ejemplo de las transformaciones protagonizadas por este objeto como resultado de la mundialización de la Edad Moderna.

Arch. esp. arte, LXXXVIII, 350, ABRIL-JUNIO 2015, 173-188 ISSN: 0004-0428, eISSN: 1988-8511, doi: 10.3989/aearte.2015.11 


\section{BIBLIOGRAFÍA}

Aguilera García, María del Carmen (coord.) (1985): El mueble mexicano. Historia, evolución e influencias, México: Fomento Cultural Banamex.

Aguiló, María Paz (1993): El mueble en España. Siglos XVI y XVII, Madrid, CSIC.

Aguiló, María Paz (2008): “Aproximaciones al estudio del mueble novohispano en España”. En: El mueble del siglo XVIII: Nuevas aportaciones a su estudio, Barcelona: Adjuntament de Barcelona, pp. 19-32.

Aguirre Anaya, C. (1997): La cerámica en la ciudad de México (1325-1917). México: Museo de la Ciudad de México.

Ajofrín, Francisco de (1986): Diario del viaje a la Nueva España, México: Sep. Cultura.

Armella de Aspe, Virginia (1990): "La influencia asiática". En: Armella de Aspe, Virginia / Castelló, Teresa / Tovar, Guillermo, la concha nácar en México, México: Gutsa, pp. 53-100.

Ávila Hernández, Julieta (1997): El influjo de la cultura china en los enconchados de la Nueva España, México: Instituto Nacional de Antropología e Historia.

Baena, Alberto (2007): "Nueva España a través de sus biombos”. En: Navarro Antolín, Fernando (ed.), Orbis incognitus: avisos y legajos del Nuevo Mundo, Huelva: Ed. Asociación de Americanistas Españoles, pp. 441-450.

Baena, Alberto (2012): “Un ejemplo de mundialización: El movimiento de biombos desde el Pacífico hasta el Atlántico (s. XVII-XVIII)", Anuario de estudios americanos, vol. 69, nº 1, pp. 31-62.

Baena, Alberto (2013): "Intercambios culturales y globalización a través del galeón de Manila: comercio y producción de biombos (s. XVII y XVIII)". En: Bernabéu, Salvador (ed.): La nao de China: navegación, comercio e intercambios culturales, Sevilla: Universidad de Sevilla, pp. 213-245.

Ballesteros, Berenice (2008): "El menaje asiático de las casas de la élite comercial del virreinato novohispano del siglo XVII", Boletín del Archivo General de la Nación, $\mathrm{n}^{\circ}$ 20, abril-junio, pp. 59-97.

Castelló Yturbide, Teresa (1972): "El maque. Lacas de Michoacán, Guerrero y Chiapas". En: Artes de México, año XIX, n 153.

Castelló Yturbide, Teresa (1981): El arte del maque en México, México: Fomento cultural Banamex.

Castelló Yturbide, Teresa y Martínez, María Josefa (1970): Biombos mexicanos, México: Instituto Nacional de Antropología e Historia.

Connors McQuade, M. (2007): Talaveras de Puebla. Cerámica colonial mexicana. Siglos XVII a XXI. Barcelona: Lunwerg Editores.

Curiel, Gustavo (1999): “Los biombos novohispanos: escenografías de poder y transculturación en el ámbito doméstico". En: Gustavo Curiel y otros, Viento detenido, mitologías e historias en el arte del biombo, México: Editorial Museo de Soumaya, pp. 9-32.

Curiel, Gustavo (2009): "Perception of the other and the language of "Chinese Mimicry" in the decorative arts of New Spain". En: Pierce, Donna and Otsuka, Ronald: Transpacific artistic cultural exchange, 1500-1850, Denver, Denver art museum, pp. 19-36.

Dujovne, Marta (1984): Las pinturas con incrustaciones de nácar, México: Instituto de Investigaciones Estéticas, UNAM.

Escalera, Andrés / Rivas Díaz, Estefanía (2002): “Un ejemplo de pintura enconchada: la virgen de la Redonda: estudio radiográfico", Anales del Museo de América, n 10, Madrid, pp. 291-305.

Escobar, Matías de (1924): Americana Thebaida (1729), México: Imp. Victoria.

García, Gabriel (2011): "Noticias acerca de pinturas y pintores de enconchados en Oaxaca", Anuario del instituto de investigaciones estéticas, México, vol. XXXIII, No 98, pp. 249-265.

García-Abásolo, Antonio (2011): "Filipinos on the Mexican Pacific Coast during the Spanish Colonial Period (1570-1630)". En: Camacho, Marya Svetlana T. (ed.), Into the Frontier. Studies on Spanish Colonial Philippines, Manila, University of Asia and the Pacific.

García-Abásolo, Antonio (2012): Murallas de piedra y cañones de seda. Chinos en el imperio español (siglos XVI-XVIII), Córdoba: Libro europeo.

García Sáiz, Ma Concepción (1992): “Precisiones al estudio de la obra de Miguel González". En: Manuel Toussaint. Su proyección en la historia del arte mexicano, México: Universidad Nacional Autónoma de México-Instituto de Investigaciones Estéticas, pp. 103-116.

Arch. esp. arte, LXXXVIII, 350, ABRIL-JUNIO 2015, 173-188

ISSN: 0004-0428, eISSN: 1988-8511, doi: 10.3989/aearte.2015.11 
García Sáiz, Ma Concepción (1993-1994): "Puente de imaginaciones. Arte colonial mexicano en España", Artes de México, $\mathrm{n}^{\circ}$ 22, México: pp. 26-39.

Gil, Juan (1991): Hidalgos y samuráis: España y Japón en los siglos XVI y XVII, Madrid: Alianza Editorial.

Granados, Rosario Inés (2000): "Guía doméstica de moralidad: un biombo novohispano del siglo XVIII". En: Mínguez, Víctor: Del libro de emblemas a la ciudad simbólica, Castellón, Publicaciones de la Universidad Jaume I, vol. 2, pp. 647-669.

Granados, Rosario Inés (2002): “Hacia la puerta norte del salón de estrado”. En: Herón y Skinfill: Esplendor y ocaso de la pintura simbólica, Michoacán, CONACYT, pp. 215-221.

Guadalupe Zuno, José (1952): "Las llamadas lacas michoacanas de Uruapan no proceden de las orientales", Cuadernos Americanos.

Kesel, W. de y Dhont, Greet (2002): Coromandel Lacquer screens, Ghent: Art Media Resources Ltd.

Lavalle-Cobo, Teresa (2003): "El coleccionismo oriental de Isabel de Farnesio". En: Alfonso Mola, Marina y Martínez Show, Carlos: Oriente en Palacio: tesoros asiáticos en las colecciones reales españolas, Madrid: Patrimonio Nacional, pp. 211-214.

León, Francisco de (1984): Los esmaltes de Uruapan, México: Editorial Innovación (1ºdición, Morelia, 1922).

Martínez del Río, María Josefa (1985): "El mueble civil”. En: El mueble mexicano. Historia, evolución e influencias, México: Fomento cultural Banamex, pp. 49-70.

Martínez del Río, María Josefa (1994): “Los biombos en el ámbito doméstico: sus programas moralizadores y didácticos". En: Tovar, Rafael / Estrada, Gerardo / Hernández, Roberto (eds.), Juegos de ingenio y agudeza, la pintura emblemática en la Nueva España, México: Museo Nacional del Arte, Ed. del Equilibrista, pp. 133-150.

Ocaña, Sonia I. (2005): Los marcos “enconchados": una vía ornamental novohispana, México DF: Tesis de maestría, UNAM, octubre.

Ocaña, Sonia I. (2008): "Marcos «enconchados«: autonomía y apropiación de formas japonesas en la pintura novohispana". Anales del instituto de investigaciones estéticas, nº 92, pp. 107-153.

Ocaña, Sonia I. (2013): "Nuevas reflexiones sobre las pinturas incrustadas de concha y el trabajo de Juan y Miguel González", Anales del Instituto de Investigaciones Estéticas, vol. 35, nº 102, pp. 125-176.

Olguín, Enriqueta M. (2004): Nácar en manos otomíes, México: UNAM y Gobierno del Estado de Hidalgo.

Oropeza, Déborah (2007): "Los «indios chinos» en la Nueva España la inmigración de la nao de China, 1565-1700", Tesis doctoral, El Colegio de México, Centro de Estudios Históricos.

Pérez Carrillo, Sonia (1987): "Imitación de la laca oriental en muebles novohispanos del siglo XVIII". En: Revista Cuadernos de Arte Colonial, no 3, pp. 51-78.

Pérez Carrillo, Sonia (1990): La laca Mexicana, Madrid: Alianza editorial.

Pérez Carrillo, Sonia y Rodríguez de Tembleque, C. (1997): "Influencias orientales y europeas" en Lacas Mexicanas, México: Museo Franz Mayer/Artes de México, Colección Uso y Estilo, $\mathrm{n}^{\circ} 5$.

Pérez de Salazar, Francisco (ed.) (2009): El mobiliario en Puebla: preciosismo, mitos y cotidianidad de la carpintería y la ebanistería. Puebla de los Ángeles: Fundación Mary Street Jenkins.

Rivas Díaz, Estefanía (2002): "El empleo de la concha nácar en la pintura virreinal: estudio radiográfico de la colección de pintura “enconchada" del museo de América de Madrid”. Espacio, Tiempo y Forma, Serie VII, Historia del Arte, 15, pp. 147-167.

Rivero Lake, Rodrigo (2005): El arte namban en el México virreinal, Madrid: Tarner.

Sanabrais, Sofía (2006): “The Biombo or folding screen in colonial México". En: Pierce, Donna y Otsuka, Ronald, Asia \& Spanish America, trans-pacific artistic and cultural exchange, 1500-1850, Denver: Simposium series, Denver Art Museum, pp. 69-106.

Sánchez Navarro, Beatriz (1985): Marfiles cristianos del Oriente en México, México: Fomento Cultural Banamex, A.C.

Stalker, J. y Parker, G. (1971): A treatise of japanning and varnishing, reimpreso en Londres: Alec Tiranti.

Vargaslugo, Elisa (1994): "La pintura de enconchados". En: México en el mundo de las colecciones de arte, México, Grupo Azabache.

Fecha de recepción: 05-V-2014

Fecha de aceptación: 31-X-2014

Arch. esp. arte, LXXXVIII, 350, ABRIL-JUNIO 2015, 173-188 ISSN: 0004-0428, eISSN: 1988-8511, doi: 10.3989/aearte.2015.11 